\title{
Citation relationships among marine biology journals and those in related fields
}

\author{
Alexander I. Pudovkin \\ Institute of Marine Biology, Far East Branch, Russian Academy of Sciences, Vladivostok 690041, Russia
}

\begin{abstract}
Simple quantitative indices of pair-wise journal citation relatedness based on the numbers of references given to a journal and received from it, provided by the Science Citation Index database) can be translated by an automatic clustering procedure into a meaningful diagram reflecting topical relatedness of journals within a field of science. Such a diagram was developed for 60 journals in marine and freshwater biology and related sciences, all published in 1987. The diagram reveals a tight cluster of marine biology journals quite distinct from the freshwater biology journal cluster or the fisheries cluster. Hence, it does not seem reasonable to regard marine, freshwater and fisheries journals as representing a single speciality as done in the Journal Citation Reports of the Science Citation Index. The journals within the marine biology cluster and those with strongest pair-wise links with them can be regarded as the core journals in marine biology.
\end{abstract}

The diagram (Fig. 1) depicts citation relatedness of 60 journals in marine biology and related fields published in 1987. This map was produced using the procedure of non-metric multidimensional scaling (Kruskal 1964) applied to a $60 \times 60$ matrix of pair-wise indices of journal citation relatedness $\left(R_{\mathrm{A}} \times \mathrm{B}\right)$ suggested by Pudovkin (1993):

$$
\begin{aligned}
& R_{\mathrm{A} \times \mathrm{B}}= \\
& {\left[H_{\mathrm{A}>\mathrm{B}} /\left(N_{\mathrm{B}} \times M_{\mathrm{A}}\right) \times 10^{6}+H_{\mathrm{A}<\mathrm{B}} /\left(N_{\mathrm{A}} \times M_{\mathrm{B}}\right) \times 10^{6}\right] / 2,}
\end{aligned}
$$

where $H_{\mathrm{A}>\mathrm{B}}=$ number of references of Journal $\mathrm{A}$ to Journal $B_{i} H_{A<B}=$ the same for Journal $B$ to Journal A; $N_{\mathrm{A}}$ and $N_{\mathrm{B}}=$ overall number of papers in year sets of Journals $A$ and $B_{i} M_{A}$ and $M_{B}=$ the same for cited references. Thus, the index $R_{\mathrm{A} \times \mathrm{B}}$ is independent of journal sizes, lengths of lists of cited references or periodicity of the journals. Each circle in the diagram represents a journal, its size being proportional to the journal size measured as the overall number of references in the yearly set of the journal.
The journals considered here are those which gave the highest number of citations to the core marine and freshwater biology journals listed in ISI's Journal Citation Reports (JCR), the latter being derived from the Science Citation Index (SCI) database. The only exception was the inclusion of a Russian language journal, Okeanologiya (Oceanology), which was not much cited by the core. This journal was included to provide a comparison with another Russian language journal, Biologiya Morya (Marine Biology), which was a core journal. The number of citations each journal receives from different speciality core journals is obtained annually by a computer routine (HayneCoulson) that is used to create the JCR database. The same routine provided the citation scores which the 60 journals gave to each other. The number of journals was limited to 60 due to technical limitations of the multi-dimensional scaling procedure used in the analysis. For a detailed discussion of the material and the results obtained, see elsewhere (Pudovkin 1993, Pudovkin \& Fuseler 1993).

One can see that the pattern of the journals' arrangement in the diagram is quite meaningful - the scaling procedure places closely related journals adjacent to each other. For instance, 5 algology journals - Botanica Marina (11), British Phycological Journal (12), Journal of Phycology (39), Aquatic Botany (42), and Phycologia (54) - are all grouped together in the lower right part of the diagram. The journals that are predominantly zoological in scope - Journal of Molluscan Studies (38), Veliger (59), Journal of Crustacean Biology (31), and Crustaceana (16) - appear together in the middle left. To emphasize this topical arrangement of journals, the author drew lines around the related journals and gave tentative names to each group.

In the center of the diagram there is a tight group of 7 marine biology publications - Marine Ecology Progress 


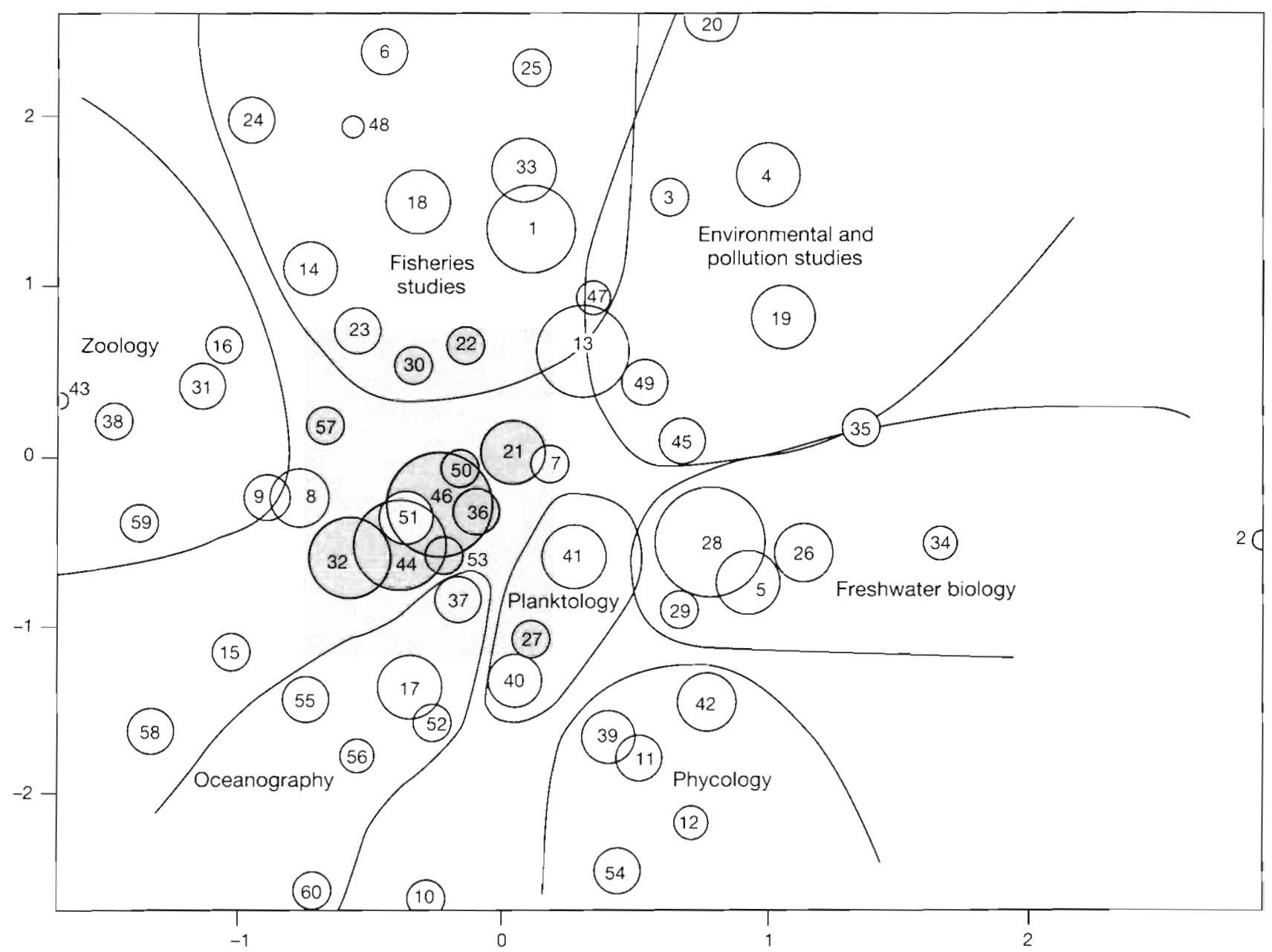

Fig. 1. Citation relatedness among 60 journals in marine biology and related fields. Each circle represents a journal, and the circle size is proportional to the overall number of references in the year set of the journal. Each journal in the diagram is automatically positioned by the procedure of non-metric multi-dimensional scaling, which processed 1770 pair-wise indices of citation relatedness obtained for the 60 journals. The axes show first (abscissa) and second (ordinate) principal components. The journals suggested as core ones in marine biology are indicated by shading. Numbers indicate journals as follows:

1 Aquaculture

2. Aquatic Insects

3. Aquatic Toxicology

4. Archives of Environmental Contamination and Toxicology

5. Archiv für Hydrobiologie

6. Arctic

7. Australian Journal of Marine and Freshwater Research

8. Bulletin of Marine Science

9. Biological Bulletin

10. Biologiya Morya (Marine Biology, Vladivostok)

11. Botanica Marina

12. British Phycological Journal

13. Canadian Journal of Fisheries and Aquatic Sciences

14. Continental Shelf Research

15. Coral Reefs

16. Crustaceana

17. Deep-Sea Research

18. Environmental Biology of Fishes

19. Environmental Pollution
20. Environmental Toxicology and Chemistry

21. Estuarine Coastal and Shelf Science

22. Estuaries

23. Fishery Bulletin

24. Fish Physiology and Biochemistry

25. Fisheries Research

26. Freshwater Biology

27. Helgoländer Meeresuntersuchungen

28. Hydrobiologia

29. Internationale Revue der Gesamten Hydrobiologie

30. Journal du Conseil

31. Journal of Crustacean Biology

32. Journal of Experimental Marine Biology and Ecology

33. Journal of Fish Biology

34. Journal of Freshwater Ecology

35. Journal of Great Lakes Research

36. Journal of the Marine Blological Association of the UK

37. Journal of Marine Research

38. Journal of Molluscan Studies
39. Journal of Phycology

40. Journal of Plankton Research

41. Limnology and Oceanography

42. Aquatic Botany

43. Marine Behaviour and Physiology

44. Marine Biology

45. Marine Chemistry

46. Marine Ecology Progress Series

47. Marine Environmental Research

48. Marine Fisheries Review

49. Marine Pollution Bulletin

50. Netherlands Journal of Sea Research

51. Oceanography and Marine Biology

52. Oceanologica Acta

53. Ophelia

54. Phycologia

55. Polar Biology

56. Marine Ecology: Publicazıoni della

Stazione Zoologica di Napoli

57. Sarsia

58. Symbiosis

59. Veliger

60. Okeanologiya (Oceanology, Moscow) 
Series (46), Marine Biology (44), Journal of the Marine Biological Association of the UK (36), Netherlands Journal of Sea Research (50), Ophelia (53), Journal of Experimental Marine Biology and Ecology (32), and Oceanography and Marine Biology (51). Evidently, the central position of the journals is determined by their broad multidisciplinary scope and high quality of papers, which in turn results in high citation rates to them from almost all of the 60 journals considered. It seems reasonable to regard 6 of these journals (omitting the annual Oceanography and Marine Biology) and 5 other journals most closely linked to the them by pair-wise ties as the core marine biology journals. Arranged alphabetically, these 11 journals are: Estuarine Coastal and Shelf Science (21), Estuaries (22), Helgoländer Meeresuntersuchungen (27), Journal du Conseil (30), Journal of Experimental Marine Biology and Ecology (32), Journal of the Marine Biological Association of the UK (36), Marine Biology (44), Marine Ecology Progress Series (46), Netherlands Journal of Sea Research (50), Ophelia (53), and Sarsía (57). These journals are marked by shading.

It is interesting to note that freshwater biology journals - Archiv für Hydrobiologie (5), Freshwater Biology (26), Hydrobiologia (28), Internationale Revue der Gesamten Hydrobiologie (29), and Journal of Freshwater Ecology (34) - form a separate tightly linked group, quite distinct from the main marine biology journal group. Thus, it does not seem reasonable to lump them under a single marine and freshwater biology category as is presently done in the JCR

Core journals in marine biology were discussed by Garfield (1980, 1987) and critically commented upon by Zhirmunsky (1980). Fuseler-McDowell (1988) described in detail the procedure for determining the marine biology core. The procedure, although welldevised and thorough, is strongly dependent on raw numbers of citations received by journals. Thus, large multidisciplinary journals, even if not specifically relevant to marine biology, may be included into the core set. As Zhirmunsky (1980) noted, this may result in a spurious merging of marine biology with other fields, which, although related, are nevertheless distinct from it.

It should be emphasized that the present study is merely a pilot. The author used a very simple index of relatedness, and there certainly may be other and more adequate indices. For instance, the index I used here $\left(R_{\mathrm{A} \times \mathrm{B}}\right)$ is the arithmetic mean of 2 unilateral

This note was submitted to the editor indices of journal relatedness, $R_{\mathrm{A}>\mathrm{B}}$ and $R_{\mathrm{A}<\mathrm{B}}$. Use of the geometric mean would perhaps be better, as it would take into account reciprocity of citation, being higher when 2 journals cite each other with equal frequency. Consistency over time and changes in the revealed citation relatedness pattern, as well as the contribution of chance fluctuations, are other relevant problems. There is one more point. The author did not take into consideration the different ages of the journals. Among the journals there are some which were relatively recently established; these would naturally receive fewer citations. The author believes that this does not greatly affect the overall pattern observed. He also hopes that this pilot study may be regarded as a point of reference for future, more comprehensive research.

Acknowledgements. The author greatly appreciates the continuing interest and encouragement for this study from Dr A. V. Zhirmunsky (Institute of Marine Biology, Vladivostok, Russia) and Dr E. Garfield (Institute for Scientific Information, Philadelphia, USA). Elizabeth Fuseler-McDowell helped the author on many occasions during his stay at ISI. Editorial comments of David Pendlebury (ISI) are gratefully appreciated. The Institute for Scientific Information provided funds for the author's sojourn in Philadelphia and use of its databases and facilities.

\section{LITERATURE CITED}

Fuseler-McDowell, E. (1988). Documenting the literature of marine biology. In: Winn, C. P., Burkhart, R. W., Burkhart, J. C. (eds.) Marine science information throughout the world: sharing the resources. IAMSLIC, St. Petersburg, Florida, p. 45-60

Garfield, E. (1980). The literature of marine biology. Biologiya Morya 3: 3-20 (In Russian). (Also published in: Sov. J Mar. Biol. 7. 137-152, 1981)

Garfield, E. (1987). Journal citation studies. 47. What oceanography journals make the biggest waves? Current Contents 30(48): 3-11

Kruskal, J. B. (1964). Multidimensional scaling by optimizing goodness-of-fit to a non-metric hypothesis. Psychometrica 29: $1-27$

Pudovkin, A. I. (1993). Journals in marine biology and adjacent area: a bibliometric study of citation links among the journals. Vladivostok (In Russian; deposited at VINITRY, Moscow)

Pudovkin, A. I., Fuseler, E. A. (1993). Indices of journal citation relatedness and citation relationships among aquatic biology journals. Scientometrics (in press)

Zhirmunsky, A, V (1980). Comments of the editor on the paper by E. Garfield. Biologiya Morya 3: 20-22 (ln Russian!

Manuscript first received: November 11, 1992

Revised version accepted: August 20, 1993 